Ömer Halisdemir Üniversitesi İktisadi ve İdari Bilimler Fakültesi Dergisi Yıl: 2021 Cilt-Sayı: 14(4) ss: 1486-1498

Academic Review of Economics and Administrative Sciences

Year: 2021 Vol-Issue: 14(4) pp: 1486-1498

http://dergipark.org.tr/tr/pub/ohuiibf

ISSN: 2564-6931

DOI: 10.25287/ohuiibf.936124

\title{
Dynamic Network Connectedness Of Brics Equity Markets During The Covid-19 ERA*
}

Onur POLAT ${ }^{\oplus 1}$

\begin{abstract}
This study examines the return and volatility network connectedness of BRICS and Turkey equity markets between January 2019 and March 2021 by utilizing the time varying parameter-VAR (TVP-VAR) based frequency connectedness approach of Barunik and Ellington (2020). In this context, we estimate short-, medium-, and longterm return and volatility network connectedness of BRICS and Turkey equity markets during an episode that covers the recent COVID-19 pandemic. Furthermore, the study focuses on the network structures of frequency return/volatility connectedness at a tranquil time (March 11, 2019) and at a turmoil time (March 11, 2020) to compare the magnitude of pairwise spillovers. Both dynamic total overall return and volatility connectedness indexes markedly surged aftermath the COVID-19 outbreak, and accordingly indicate the significant impact of the COVID-19 on the BRICS and Turkey equity markets connectedness. Network structures of dynamic return and volatility connectedness indicate remarkably amplified pairwise spillovers on March 11, 2020.
\end{abstract}

Keywords : Dynamic networks, TVP-VAR, Pairwise spillovers, Financial connectedness.

Jel Classification :C10, C40, C58.

*This paper is a revised and expanded version of a paper entitled "Dynamic Frequency Connectedness of BRICS Stock Markets Nexus COVID-19: A TVP-VAR Frequency Connectedness Approach" presented at FSCONGRESS-2021, Virtual Mode, 7-8 May 2021.

${ }^{1}$ Doç. Dr., Bilecik Şeyh Edebali Üniversitesi, İ.İ.B.F., Maliye, onur.polat@bilecik@edu.tr, ORCID: 0000-0002-7170-4254 


\title{
Brics Hisse Senedi Piyasalarinin Covid-19 Dönemi DíNAMíK Ă̆ BAĞLANTILILIĞI
}

\begin{abstract}
$\ddot{\boldsymbol{O} z}$
Bu çalışma, BRICS ülkeleri ve Türkiye hisse senedi piyasaları arasındaki getiri ve oynaklık ă̆ bağlantılılıklarını, Barunik ve Ellington'un (2020) zamanla değişen parametreli-VAR (TVP-VAR) tabanl frekans bağlantılılı̆̆ yaklaşımını kullanarak Ocak 2019 ve Mart 2021 döneminde incelemektedir. Bu bă̆lamda, COVID-19 küresel salgınını kapsayan bir dönemde BRICS ülkeleri ve Türkiye hisse senedi piyasaları arasındaki kısa, orta ve uzun vadeli getiri ve oynaklık ăg băglantılılıkları tahmin edilmektedir. Ek olarak, çalışma ikili yayılmaların büyüklügünü karşılaştırmak için piyasaların sakin olduğu (11 Mart 2019) ve çalkantılı olduğu (11 Mart 2020) iki farklı zamanda frekans getiri/oynaklık bağlantılılıklarının ağ yapılarını incelemektedir. Dinamik toplam getiri ve oynaklık bağlantılılıkları, COVID-19 küresel salgınının ortaya çıkmasından hemen sonra önemli ülçüde yükselmekte ve dolayıslyla COVID-19'un BRICS ülkeleri ve Türkiye hisse senedi piyasaları bağlantılılı̆̆l üzerindeki önemli etkisini göstermektedir. Dinamik getiri ve oynaklık ă̆ bağlantılılıklarl, 11 Mart 2020'de önemli seviyede yükselen ikili yayılmalara işaret etmektedir.
\end{abstract}

Anahtar Kelimeler $\quad$ : Dinamik ağlar, TVP-VAR, İkili taşmalar, Finansal bağlantılılık.

Jel Sinıflandirmasi $\quad$ : C10, C40, C58.

\section{INTRODUCTION}

The financialization era has been accompanied by deep and prolonged financial/geopolitical imbalances. Despite these upheavals sorely hit the world economic system, it has recovered from them eventually and has kept its continued expanding trend. Among these economic downturns, the 2008 global financial crisis is the most severe since the 1929 great depression, and the real global GDP contracted by 1.3 percentage in 2009 (Chandy et al., 2009). The global economy has witnessed several turmoils in the post-GFC epoch, yet the recent COVID-19 pandemic has grievously affected economic activity.

The novel coronavirus first emerged in the Chinese municipality, Wuhan, in late 2019 and rapidly spread to the rest of the world. As of April 3, 2021, the total number of COVID-19 cases has surpassed 130 million, and the number of deaths is close to 3 million. Despite launching vaccination in early 2020, the number of identified cases persists in its geometric increasing trend, particularly in the low and medium-income countries.

The COVID-19 pandemic stemmed from one of the BRICS (Brazil, Russia, India, China, and South Africa) country, and has severely hit the BRICS and other emerging economies. Brazil, India, and Russia rank 2nd, 3rd, and 5th countries with regards to total confirmed cases (12.7 million, 12.3 million, and 4.5 million as of April 3, 2021, respectively) ${ }^{2}$, and accordingly, the pandemic has devastative impacts on BRICS economies as well as on other emerging economies. The novel coronavirus pandemic has had devestative effects on emerging stock markets (Salisu et al., 2020; Topcu and Gulal, 2020).

As extensively examined by scholars, connectedness between financial assets prones to intensify around financial/geopolitical bursts (Barigozzi et al., 2020; Fernández-Rodríguez \& Sosvilla-Rivero, 2020; Lee \& Lee, 2020; Polat, 2020). The COVID-19 pandemic sets an example for such a geopolitical turmoil and connectedness between financial markets has dramatically soared following the pandemic (Bissoondoyal-Bheenick et al., 2020; Bouri et al., 2020; So et al., 2020). Departing from this phenomenon, we aim to analyze return and volatility connectedness networks for selected emerging economies which have been severely hit by the COVID-19 pandemic. Our main hypothesis is that the COVID-19 pandemic conduced to a significant surge in both return and volatility connectedness among emerging stock markets.

\footnotetext{
${ }^{2}$ See https://covid19.who.int/.
} 
Given the monumental impact of the COVID-19 pandemic on BRICS stock markets, this study examines return and volatility connectedness for equity markets of BRICS countries. To this end, we utilize the TVP-VAR frequency connectedness approach of Barunik \& Ellington (2020). By doing so, we compute the short-, medium-, and long-term dynamic return and volatility connectedness for BRICS countries on January 7, 2019, and March 3, 2021.

Our contributions to the extant literature are three folds. First, we compute dynamic return and volatility connectedness between BRICS countries during the COVID-19 pandemic by implementing a novel methodology. Second, we estimate the short-, medium-, and long-term dynamic network connectedness by implementing a locally stationary TVP-VAR relying on QuasiBayesian Local Likelihood (QBLL) methods. Third, we analyze return and volatility network connectedness of pairwise spillovers between BRICS countries that evolve over time. To our knowledge, this is the first study to examine the frequency network structures of return and volatility connectedness of emerging stock markets and the COVID-19 pandemic's impact on them.

The remainder of the study is structured as follows: Section 2 provides a brief literature review on the network structure of financial connectedness. Section 3 delineates the methodology and the data of the work. Section 4 discusses empirical results the study. Section 5 draws main findings of the work and concludes it.

\section{LITERATURE REVIEW}

Global financial markets are tightly connected through a variety of channels, which conduces rapid and excessive risk spillovers between them particularly during financial burst episodes (Cheung et al., 2010; Hesse \& Frank, 2010; De Bruyckere et al., 2013; Yang and Zhou, 2013; Wang et al., 2016; Wen et al., 2019; Su, 2020). Strong interdependence between financial variables motivates a strand of literature examining the network structure of connectedness and its propagation mechanisms into finance and economics.

It is worth noticing that network theory is a relatively new concept for finance and economics fields and was originally based on the graph theory. A pioneering study, Erdős \& Rényi (1959) theoretically analyzed an early version of network models, known as network graphs. In this simple version of the network model, any two nodes are linked with an independent and identical probability, denoted by the Erdős-Rényi probability. One of the earliest studies in finance, Eboli (2004) utilized the theory of network flows to analyze the network structure of defaults in the financial system. The author used a financial network in which banks (nodes) are linked in regards to their losses are propagated via a sink channel. Likewise, D'Errico et al. (2009) analyzed the shareholding network in Italian stock market by using betweenness and flow betweenness centrality measures. Along similar lines, Nier et al. (2010) constructed a network system that consists of a number of banks linked by interbank connections. In a similar vein, Saltoglu \& Yenilmez (2010) developed a network model to understand the dynamics of the GFC and utilized various network measures such as links, interconnectivity and reciprocity.

It should be noted that scholars have employed different connectivity measures to link nodes in a network model, yet a comprehensive study developed the population connectedness based on estimating forecast error variance shares of a VAR model (Diebold \& Yilmaz, 2014). The authors then computed static and dynamic (rolling) network volatility connectedness of 13 US financial institutions between May 1999, and April 2010. This groundbreaking approach has received overwhelming interest from scholars, and studies have estimated network connectedness among various markets. In this vein, Diebold et al. (2017) computed network volatility connectedness between 19 commodity price indexes. Similarly, Mensi et al. (2018) constructed a network of volatility spillovers between GIPSI stock markets from January 2, 2002, and May 4, 2016. Demirer et al. (2018) estimated VAR-LASSO-based 
high-dimensional network linkages between 150 banks by utilizing the population connectedness approach in 2003-2014. Likewise, Kang et al. (2019) constructed dynamic network connectedness between economic policy uncertainty (EPU) indexes of G-7 countries, China, and the EU from 1997 to 2016. More recently. Antonakakis et al. (2020) enhance the population connectedness approach by using the time-varying parameter vector autoregressive (TVP-VAR) model and estimated network return connectedness of four monthly exchange rates. Notice that the network linkages not only exhibit temporary dependence, but they also display different frequency characteristics. In this context, Barunik \& Ellington (2020) introduced frequency-dependent network model based on a locally stationary TVPVAR model using QBLL methods. This novel methodology renders it possible to integrate prior shrinkage and to compute uncertainty from the posterior distribution of the network. This methodology is superior to conventional works that allows only point estimations relied on bootstrapping for confidence intervals and computationally inefficient. The authors constructed short-, medium-, and long-term volatility network connectedness for 496 stocks from New York Stock Exchange (NYSE) between July 5, 2005, and August 31, 2018.

\section{DATA AND METHODOLOGY}

\section{II.I. Data}

We use stock market indexes for BRICS countries namely, IBOVESPA (USD-REAL), IMOEX (USD-RUB), S\&P BSE SENSEX (USD-RUP), Shanghai Composite Index (USD-YUAN), FTSE South Africa (USD-ZAR), and BIST (USD-TRY) between January 4, 2019, and March 3, 2021. We collected data from the investing.com database ${ }^{3}$.

\section{II.II. Methodology}

Barunik \& Ellington (2020) build a network dynamic using spectral representation of time varying variance decomposition matrices. In doing so, they capture the impact of a transitory and permanent shocks from variable $i$ to future variance of variable $j$ and specify a dynamic adjacency matrix, which consists of the all information regarding the network.

Define the following $N$-variate time series $\left(Y_{t, T}\right)_{1 \leq t \leq T, T \in N}$ with elements of $Y_{t, T}=$ $\left(Y_{t, T}^{1}, \ldots, Y_{t, T}^{N}\right)^{T}$. Herein, $t$ corresponds to the time index, $T$ is an additional index representing the "sharpness of the local approximation of the time series $\left(Y_{t, T}\right)_{1 \leq t \leq T, T \in N}$ by a stationary one" (Barunik and Ellington, 2020:7).

We posit that $\left(Y_{t, T}\right)_{1 \leq t \leq T, T \in N}$ follow a locally stationary TVP-VAR of lag order of $q$ :

$$
Y_{t, T}=\emptyset_{1}(t / T) Y_{t-1, T}+\cdots+\emptyset_{q}(t / T) Y_{t-q, T}+\varepsilon_{t, T}
$$

where,

$$
\varepsilon_{t, T}=\Sigma^{-\frac{1}{2}}(t / T) \xi_{t, T} \text { with } \xi_{t, T} \sim N I D\left(0, I_{M}\right), \text { and } \emptyset(t / T)=\left(\emptyset_{1}(t / T), \ldots, \emptyset_{q}(t / T)\right)^{T}
$$

are time-varying autoregressive coefficients. In a neighborhood of fixed time $v_{0}=t_{0} / T$, the process $Y_{t, T}$ is approximated by a stationary process $\tilde{Y}_{t}\left(v_{0}\right)$ as:

$$
\tilde{Y}_{t}\left(v_{0}\right)=\emptyset_{1}\left(t_{0}\right) \tilde{Y}_{t-1}\left(t_{0}\right)+\cdots+\emptyset_{q}\left(t_{0}\right) \tilde{Y}_{t-q}\left(t_{0}\right)+\varepsilon_{t}
$$

\footnotetext{
${ }^{3}$ See https://www.investing.com/indexes/.
} 
Polat, O. (2021). Dynamic network connectedness of BRICS equity markets during the Covid-19 era. Ömer Halisdemir Üniversitesi İktisadi ve İdari Bilimler Fakültesi Dergisi, 14(4), 1468-1498.

$t \in Z$ and satisfies $\left|Y_{t, T}-\tilde{Y}_{t}\left(t_{0}\right)\right|=O_{q}\left(\left|t / T-v_{0}\right|+1 / T\right)$. Thence, the time-varying $V M A(\infty)$ representation of the process can be given as:

$$
Y_{t, T}=\sum_{h=-\infty}^{\infty} \Psi_{t, T}(h) \varepsilon_{t-h}
$$

where $\Psi_{t, T} \approx \phi(t / T, h)$ is a stochastic process with $\sup _{l}\left\|\Psi_{t}-\Psi_{l}\right\|^{2}$ for $1 \leq h \leq t$ as $t \rightarrow \infty$. The spectral density of $Y_{t, T}$ at frequency $w$ is introduced as:

$$
S_{Y}(v, w)=\sum_{h=-\infty}^{\infty} \mathrm{E}\left[\tilde{Y}_{t+h}(v) \tilde{Y}_{t}^{T}(v)\right] e^{-i w h}=\left\{\Psi(v) e^{-i w}\right\} \Sigma(v)\left\{\Psi(v) e^{+i w}\right\}^{T}
$$

Assume that $Y_{t, T}$ is weakly locally stationary process with $\sigma_{k k}^{-1} \sum_{h=0}^{\infty}\left|\left[\Psi(v) e^{-i w} \Sigma(v)\right]_{j, k}\right|^{2}<$ $\infty, \forall j, k$. "Then, the time-frequency variance decompositions of the $j$ th variable at a rescaled time $v=$ $t_{0} / T$ due to shock in $k$ th variable on the frequency band $d=(a, b): a, b \epsilon(-\pi, \pi), a<b$ form a dynamic adjacency matrix" (Barunik \& Ellington, 2020: 8) as:

$$
[\theta(v, d)]_{j, k}=\frac{\sigma_{k k}^{-1} \int_{a}^{b}\left|\left[\Psi(v) e^{-i w} \Sigma(v)\right]_{j, k}\right|^{2} d w}{\int_{-\pi}^{\pi}\left[\left\{\Psi(v) e^{-i w}\right\} \Sigma(v)\left\{\Psi(v) e^{-i w}\right\}^{T}\right]_{j, j} d w}
$$

Barunik and Ellington (2020) define local network connectedness as:

$$
C(v, d)=100 \times \sum_{\substack{j, k=1 \\ j \neq k}}^{N}[\tilde{\theta}(v, d)]_{j, k} / \sum_{\substack{j, k=1 \\ j \neq k}}^{N}[\tilde{\theta}(v)]_{j, k}
$$

The local directional connectedness (FROM connectedness) that gauges how much of each indicator's $j$ variance owing to shocks in other indicators $k \neq j$ is introduced as:

$$
C_{j \leftarrow \cdot}(v, d)=100 \times \sum_{\substack{k=1 \\ k \neq j}}^{N}[\tilde{\theta}(v, d)]_{j, k} / \sum_{j, k=1}^{N}[\tilde{\theta}(v)]_{j, k}
$$

Similarly, the contribution of $j$ to variances in other indicators is calculated as:

$$
C_{j \rightarrow \cdot}(v, d)=100 \times \sum_{\substack{k=1 \\ k \neq j}}^{N}[\tilde{\theta}(v, d)]_{k, j} / \sum_{k, j=1}^{N}[\tilde{\theta}(v)]_{k, j}
$$


Polat, O. (2021). Dynamic network connectedness of BRICS equity markets during the Covid-19 era. Ömer Halisdemir Üniversitesi İktisadi ve İdari Bilimler Fakültesi Dergisi, 14(4), 1468-1498.

\section{EMPIRICAL FINDINGS}

Figure 1 exhibits movements of stock market indexes for BRICS countries and Turkey between January 4, 2019 and March 3, 2021.

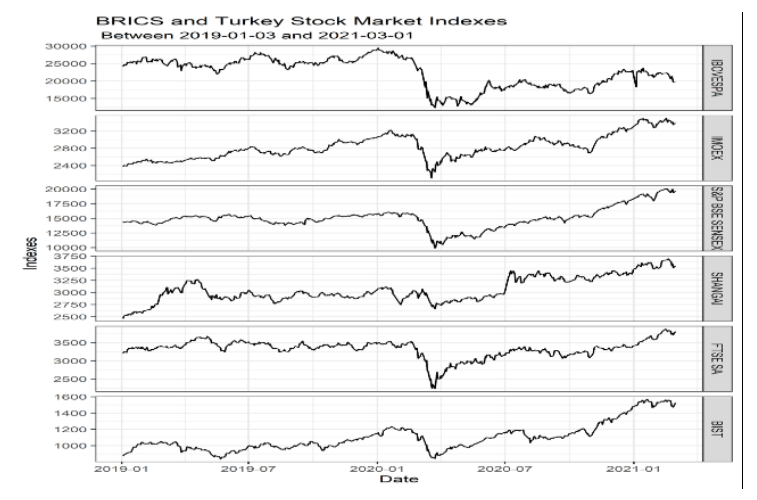

Figure 1. BRICS Stock Market İndexes in January 4, 2019 and March 3, 2021

As Figure 1 indicates that BRICS and Turkey stock market indexes dramatically between the first quarter of 2020 and late March 2020 due to the COVID-19 pandemic, and have exhibited an increasing trend, thenceforth. On the other hand, the COVID-19 pandemic has limited effect on the equity market of China as compared to other countries.

\section{III.I. Dynamic Return and Volatility Networks for BRICS Stock Markets}

In this sub-section, we estimate network return and volatility connectedness for BRICS and Turkey equity market indexes by utilizing the methodology of Barunik \& Ellington (2020). Figure 2 exhibits total dynamic network return connectedness for BRICS and Turkey equity market indexes with median and $2.5 \%$ and $97.5 \%$ quantiles ${ }^{4}$.

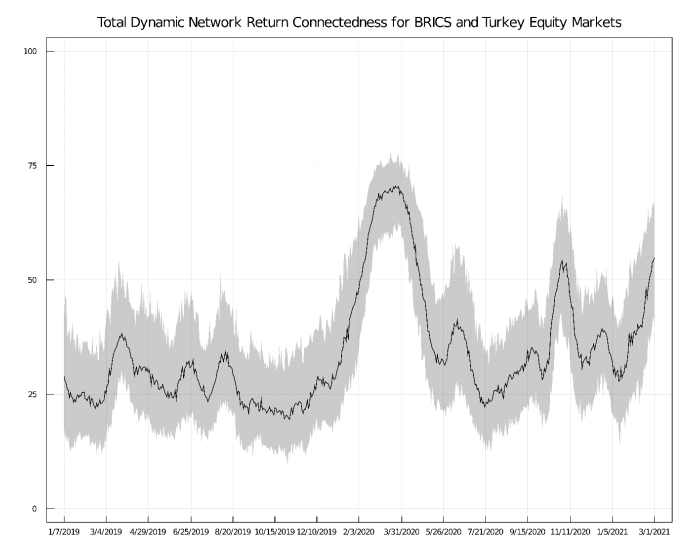

Figure 2. Total Dynamic Network Return Connectedness for BRICS and Turkey Stock Markets

The total dynamic network return connectedness index oscillates between $19 \%$ and $71 \%$ over the study period. The overall dynamic connectedness peaks on March 23, 2020 (70.54\%), which is shortly

\footnotetext{
${ }^{4}$ We choose the optimal order of the VAR as 1 by the Akaike Information Criterion (AIC) and the Bayesian Information Criterion (BIC). We run Julia 1.5.3 program and use packages available at https://github.com/barunik/DynamicNets.jl.
} 
Polat, O. (2021). Dynamic network connectedness of BRICS equity markets during the Covid-19 era. Ömer Halisdemir Üniversitesi İktisadi ve İdari Bilimler Fakültesi Dergisi, 14(4), 1468-1498.

after the official announcement of the COVID-19 pandemic by the World Health Organization (WHO), and reaches its trough on November 04, 2019 (19.48\%). The index has surged starting from January 2021, and surpassed 50\%. As well evidenced in the related literature, the connectedness between financial assets prone to soar around financial/geopolitical bursts (Diebold and Yilmaz, 2014; Ahmad et al, 2018; Gong et al., 2019; Lin and Chen, 2021).

Next, we compute short-, medium-, and long-term ${ }^{5}$ dynamic network return connectedness for BRICS and Turkey equity markets and depict them in Figure 3.

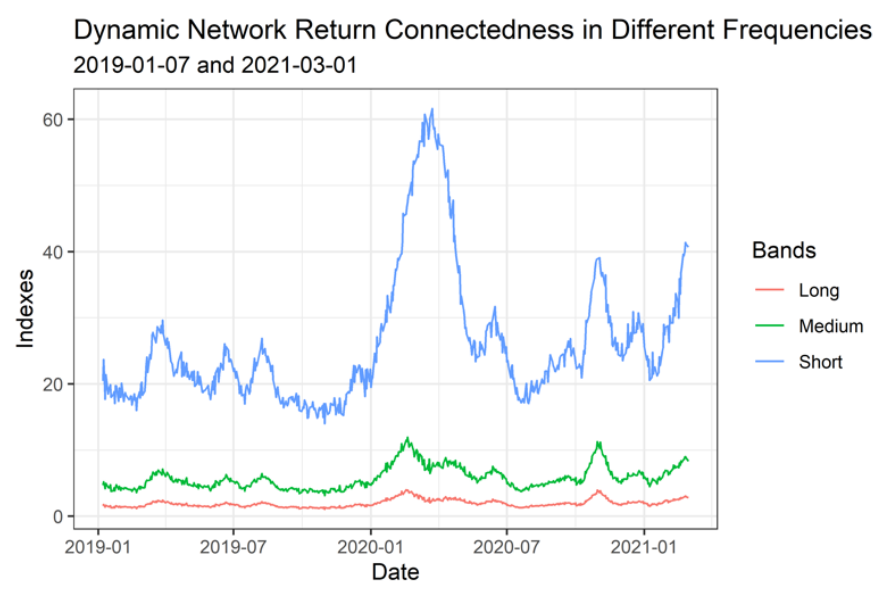

Figure 3. Short-. Medium-, Long Term Dynamic Network Return Connectedness for BRICS and Turkey Stock Markets

As Figure 3 plainly depicts that the medium-, and long-term dynamic network return connectedness exhibit similar patterns, whereas the short-term return connectedness disparates from them particularly during the first quarter of 2020. The short-term return connectedness peaks on March 23, 2020 with $61.63 \%$, whereas the medium-, and long-term return connectedness hit their apexes on February 19, 2020, and on February 17, 2020 with 11.9\%, and 3.99\%, respectively. Accordingly, sharing a common feature, all series peak aftermath the outbreak of the COVID-19 pandemic. This finding underlines the significant impact of the COVID-19 pandemic on the BRICS and Turkey equity markets return connectedness.

In the next step, we estimate dynamic network volatility ${ }^{6}$ connectedness for BRICS equity market indexes with median and $2.5 \%$ and $97.5 \%$ quantiles $^{7}$.

\footnotetext{
${ }^{5}$ Short-, medium-, and long-term connectedness approximately reflects to 1-5 days (up to one week), 5-20 days (week up to month), and 20 + days (more than month), respectively.

${ }^{6}$ We estimate historical volatilities by implementing $\operatorname{GARCH}(1,1)$ model with the smallest AIC and BIC.

${ }^{7}$ We select the optimal VAR order as 5 by the AIC and BIC.
} 
Polat, O. (2021). Dynamic network connectedness of BRICS equity markets during the Covid-19 era. Ömer Halisdemir Üniversitesi İktisadi ve İdari Bilimler Fakültesi Dergisi, 14(4), 1468-1498.

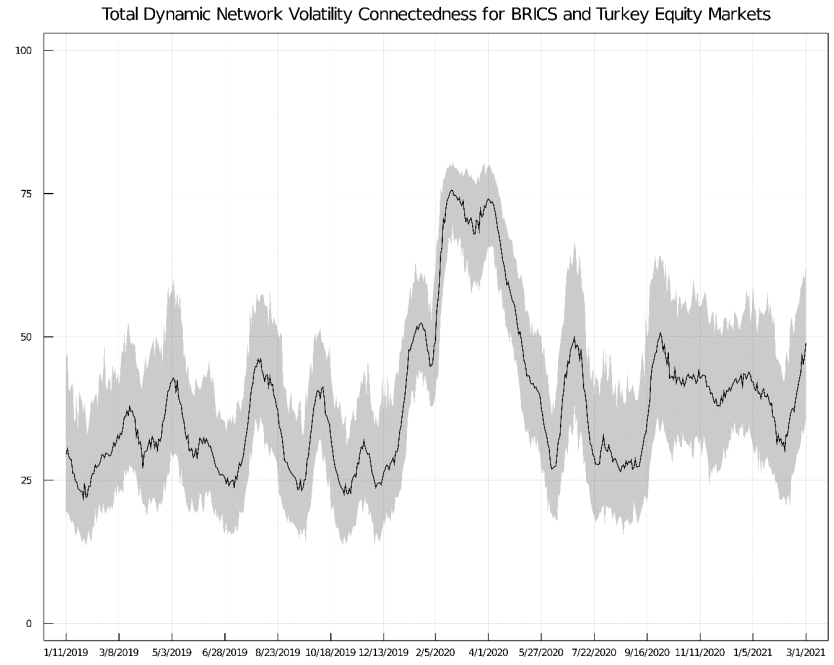

Figure 4. Total Dynamic Network Volatility Connectedness for BRICS and Turkey Stock Markets

Overall dynamic volatility connectedness for BRICS and Turkey equity markets fluctuates between $21 \%$ and $76 \%$ over the study period and peaks on February 24, 2020 (75.55\%). Similar to the total dynamic return connectedness, the index has slightly surged in the recent period.

Next, ee estimate short-, medium-, and long-term dynamic network volatility connectedness for BRICS and Turkey equity markets and depict them in Figure 5.

\section{Dynamic Network Volatility Connectedness in Different Frequencies} 2019-01-11 and 2021-03-01

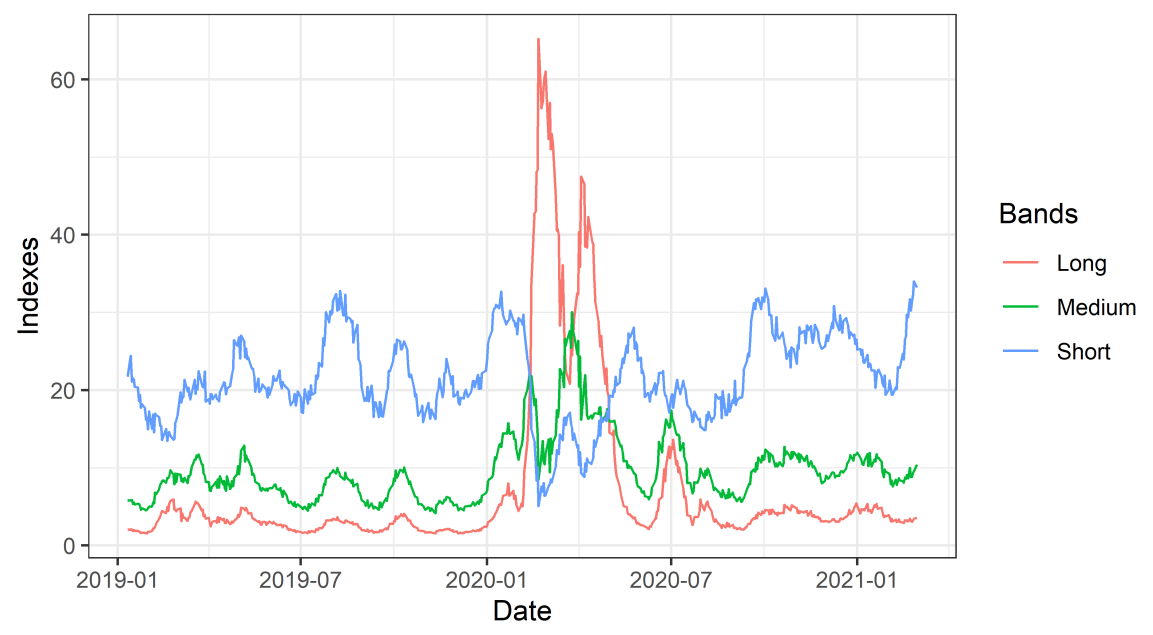

Figure 5. Network Short-. Medium-, Long Term Dynamic Network Volatility Connectedness for

\section{BRICS Stock Markets}

As presented in Figure 5, long-, and medium-term dynamic network volatility connectedness display similar patterns except for the first quarter 2020, in which the COVID-19 pandemic soarly hit the global financial markets. This finding also highlights that the long-term volatility connectedness during turmoil times are stronger than the short-term connectedness and consistent with the findings in Barunik and Ellington (2020). 
Polat, O. (2021). Dynamic network connectedness of BRICS equity markets during the Covid-19 era. Ömer Halisdemir Üniversitesi İktisadi ve İdari Bilimler Fakültesi Dergisi, 14(4), 1468-1498.

\section{III.II. Dynamic Network Connectedness Analysis}

In this sub-section, we focus on the network structures over the short-term and long-term by using the adjacency matrix. Since a vast amount of connectedness stemmed in the short-term for network return connectedness, we concentrate on the short-term network return connectedness for BRICS equity markets. To focus on the impact of the COVID-19 pandemic on equity connectedness, we estimate short-term connectedness at a tranquil time (March 11, 2019) and, amid the COVID-19 pandemic (March 11, 2020). Figure 6 shows short-term network return connectedness for these two-time points. In the network analysis, the size of each node reflects the amount of total TO spillovers from that node.

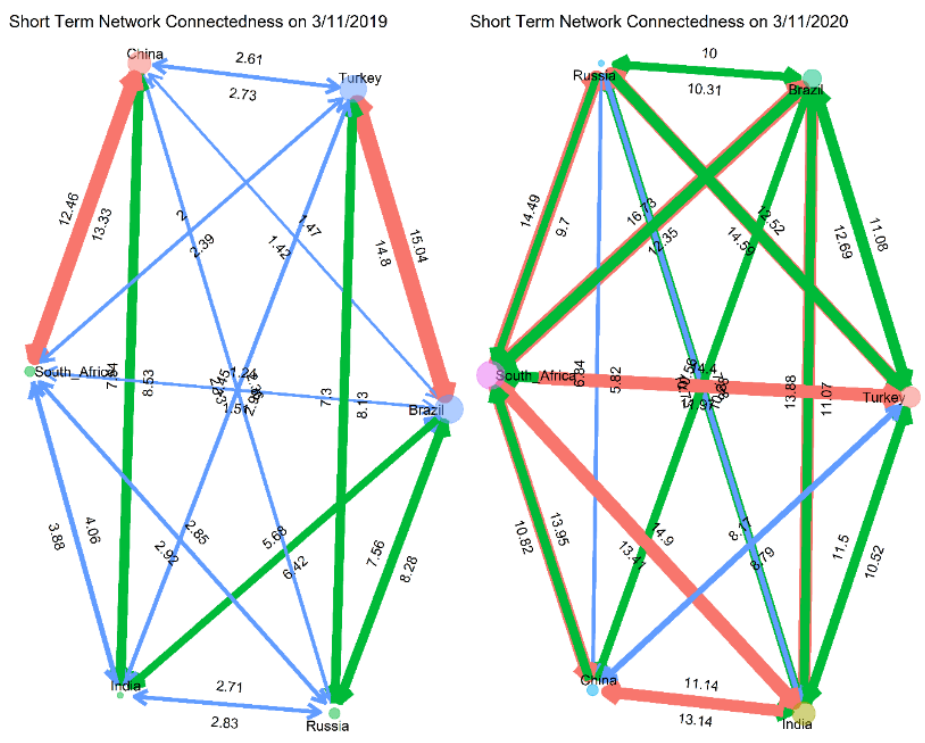

Figure 6: Short-Term Network Structure of BRICS and Turkey Equity Markets Return

\section{Connectedness}

The short-term network return connectedness on March 11, 2019 indicates that Brazil and Turkey catalyst the largest amount of total TO spillovers with $32.4 \%$ and $31.2 \%$, respectively, and India spreads the lowest amount of total TO spillovers with $22.6 \%$. Brazil and Turkey pair has the strongest connectedness which is in line with the findings of Taşdemir and Yalama (2014). China and South Africa are strongly interconnected with $12.4 \%$ and $13.3 \%$ directional connectedness. Brazil and China pair has the weakest connectedness.

On March 11, 2020, which coincides with the COVID-19 announcement of the WHO, South Africa and India catalyst the largest amount of total TO spillovers with $74.4 \%$ and $62.6 \%$, whilst Russia disperses the lowest amount of total TO spillover (46\%). With the COVID-19 outbreak, the pairwise spillovers remarkably amplified on March 11, 2020. South Africa-India, South Africa-Turkey, and China-India pairs have the strongest connectedness. Contrariwise, the China-Russia pair has the weakest interdependence.

We estimate long-term network volatility connectedness since long-term connectedness is more intensified than short-, and medium-term connectedness particularly during the first quarter of 2020 due to the COVID-19 pandemic. Figure 7 presents long-term network volatility connectedness on March 11, 2019, and on March 11, 2020, respectively. 


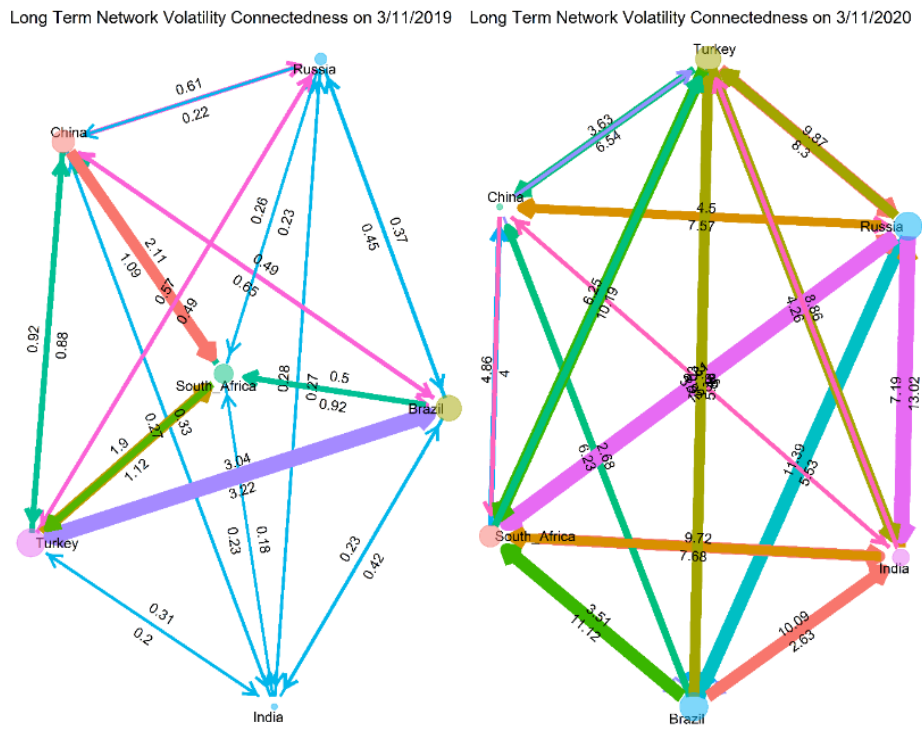

Figure 7. Long-Term Network Structure of BRICS Equity Markets Volatility Connectedness

Long-term network volatility connectedness perceptibly indicates that the volatility interconnectedness of BRICS and Turkey equity markets dramatically amplified owing to the COVID19 pandemic. On March 11, 2019, Turkey and Brazil transmit the highest total TO spillovers (6.7\%, and 5.6\%, respectively). On the contrary, India propagates the lowest total TO spillovers $(1.2 \%)$. The Turkey-Brazil pair has the strongest connectedness, whilst the Russia-South Africa pair has the weakest interconnectedness.

With the official announcement of the COVID-19 pandemic, Brazil and Russia catalyst the largest total TO spillovers (47.8\%, and 47.7\%, respectively), and followed by Turkey (40\%), South Africa (34.1\%), India (25.6\%), and China (18.7\%). The Russia-South Africa (13.3\%), Russia-India (13.02\%) pairs have the strongest interdependencies, whereas the India-Brazil pair $(2.62 \%)$ has the weakest connectedness.

\section{CONCLUSION}

The world economy witnessed one of the deepest and drastic turmoil with the emergence of the COVID-19 pandemic, which conduced to a 3.3\% decline in the global output in 2020 (IMF, 2021). Despite fiscal/monetary stimulus enacted by the governments and launching vaccination in early 2021, the global prospects remain highly uncertain, and the pandemic has continued to spread at an increasing rate, particularly in emerging and less developed countries.

This study focuses on the impact of the COVID-19 pandemic on the dynamic return and volatility connectedness networks for the BRICS and Turkey equity markets. In this context, we utilize the TVP-VAR frequency connectedness approach based on QBLL methods. By doing so, we estimate short-, medium-, and long-term connectedness return and volatility networks for BRICS and Turkey equity markets in January 2019 and March 2021.

Sharing a common feature, total dynamic return/volatility connectedness indexes gradually soar starting from January 2020 and hit their apexes in February/March 2020. On the other hand, dynamic short-, medium-, and long-term network return/volatility connectedness exhibit different characteristics. For example, short-term network return connectedness skyrockets in March 2020 while medium-, and long-term network return connectedness remain silent, long-term network volatility interdependence are stronger than short-, and medium-term network volatility linkages. We also focus on the network structure of dynamic return/volatility connectedness BRICS and Turkey equity markets at a calm time (March 11,2019) and a turmoil time (March 11, 2020). 
Both short-term network of dynamic return connectedness and long-term network of dynamic volatility connectedness highlight a significant increase in the magnitude of pairwise spillovers for the latter time.

Both return and volatility connectedness networks of emerging stock markets in diffferent frequencies underline the noteworthy impact of the COVID-19 pandemic on emerging stock markets and consistent with the previous studies (Ashraf, 2020; Aslam et al, 2020; Liu et al., 2020; Belaid et al., 2021).

The recent COVID-19 pandemic has precipitously hit the global financial markets and the world has confronted with the worst economic downturn since the World War II (The World Bank, 2020). In view of this, the key policy suggestions of this paper can be given as follows: First, authorities and policymakers should continue to enact fiscal/monetary stimulus to alleviate the detrimental effects of the crisis. Second, regulators should closely monitor systemic risk contagion to prevent the financial system from unprecedented shocks.

\section{REFERENCES}

Ahmad, W., Mishra, A. V., \& Daly, K. J. (2018). Financial connectedness of BRICS and global sovereign bond markets. Emerging Markets Review, 37, 1-16.

Antonakakis, N., Chatziantoniou, I., \& Gabauer, D. (2020). Refined measures of dynamic connectedness based on time-varying parameter vector autoregressions. Journal of Risk and Financial Management, 13(4), 84. Ashraf, B. N. (2020). Stock markets' reaction to COVID-19: Cases or fatalities?. Research in International Business and Finance, 54, 101249.

Aslam, F., Mohmand, Y. T., Ferreira, P., Memon, B. A., Khan, M., \& Khan, M. (2020). Network analysis of global stock markets at the beginning of the coronavirus disease (Covid-19) outbreak. Borsa Istanbul Review, 20, 49-61.

Barigozzi, M., Hallin, M., Soccorsi, S., \& von Sachs, R. (2020). Time-varying general dynamic factor models and the measurement of financial connectedness. Journal of Econometrics, 222(1B), 324-343.

Barunik, J., \& Ellington, M. (2020). Dynamic Networks in Large Financial and Economic Systems. Retrieved from: https://arxiv.org/abs/2007.07842.

Belaid, F., Ben-Amar, A., Goutte, S., \& Guesmi, K. (2021). Emerging and advanced economies markets behaviour during the COVID-19 crisis era. International Journal of Finance \& Economics. DOI:10.1002/ijfe.2494.

Bissoondoyal-Bheenick, E., Do, H., Hu, X., \& Zhong, A. (2020). Learning from SARS: Return and Volatility Connectedness in COVID-19. Finance Research Letters, 101796.

Bouri, E., Cepni, O., Gabauer, D., \& Gupta, R. (2021). Return connectedness across asset classes around the COVID-19 outbreak. International Review of Financial Analysis, 73, 101646.

Chandy, L., Gertz, G., \& Linn, J. (2009). Tracking the global financial crisis: An analysis of the IMF's world economic outlook. Wolfensohn Center for Development at Brookings. Retrieved from http://www.

brookings.edu/reports/2009/05_financial_crisis_linn. aspx.

Cheung, W., Fung, S., \& Tsai, S. C. (2010). Global capital market interdependence and spillover effect of credit risk: evidence from the 2007-2009 global financial crisis. Applied Financial Economics, 20(1-2), 85103.

De Bruyckere, V., Gerhardt, M., Schepens, G., \& Vander Vennet, R. (2013). Bank/Sovereign risk spillovers in the European debt crisis. Journal of Banking \& Finance, 37(12), 4793-4809.

Diebold, F. X., \& Y1lmaz, K. (2014). On the network topology of variance decompositions: Measuring the connectedness of financial firms. Journal of econometrics, 182(1), 119-134.

Demirer, M., Diebold, F. X., Liu, L., \& Yilmaz, K. (2018). Estimating global bank network connectedness. Journal of Applied Econometrics, 33(1), 1-15.

D'Errico, M., Grassi, R., Stefani, S., \& Torriero, A. (2009). Shareholding networks and centrality: an application to the Italian financial market. In Networks, Topology and Dynamics (pp. 215-228). Berlin: Springer.

Diebold, F. X., Liu, L., \& Y1lmaz, K. (2017). Commodity connectedness (No. w23685). National Bureau of Economic Research. Retrieved from: https://www.nber.org/papers/w23685. 
Polat, O. (2021). Dynamic network connectedness of BRICS equity markets during the Covid-19 era. Ömer Halisdemir Üniversitesi İktisadi ve İdari Bilimler Fakültesi Dergisi, 14(4), 1468-1498.

Diebold, F. X., \& Y1lmaz, K. (2014). On the network topology of variance decompositions: Measuring the connectedness of financial firms. Journal of Econometrics, 182(1), 119-134.

Eboli, M. (2004). Systemic risk in financial networks: A graph theoretic approach. Universita di Chieti Pescara.

Erdős, P., \& Rényi, A. (1959). On random graphs. Publicationes Mathematicae, 6, 290-297.

Fernández-Rodríguez, F., \& Sosvilla-Rivero, S. (2020). Volatility transmission between stock and foreign exchange markets: A connectedness analysis. Applied Economics, 52(19), 2096-2108.

Hesse, H., \& Frank, N. (2009). Financial spillovers to emerging markets during the global financial crisis. IMF Working Papers, 1-20.

IMF (2021). World Economic Outlook. Retrieved from: https://www.imf.org/en/Publications/WEO/Issues/2021/03/23/world-economic-outlook-april-2021.

Lee, H. S., \& Lee, W. S. (2020). Network Connectedness among Northeast Asian Financial Markets. Emerging Markets Finance and Trade, 56(13), 2945-2962.

Lin, S., \& Chen, S. (2021). Dynamic connectedness of major financial markets in China and America. International Review of Economics \& Finance, 75, 646-656.

Liu, H., Manzoor, A., Wang, C., Zhang, L., \& Manzoor, Z. (2020). The COVID-19 outbreak and affected countries stock markets response. International Journal of Environmental Research and Public Health, 17(8), 2800 .

Mensi, W., Boubaker, F. Z., Al-Yahyaee, K. H., \& Kang, S. H. (2018). Dynamic volatility spillovers and connectedness between global, regional, and GIPSI stock markets. Finance Research Letters, 25, 230-238.

Nier, E., Yang, J., Yorulmazer, T., \& Alentorn, A. (2007). Network models and financial stability. Journal of Economic Dynamics and Control, 31(6), 2033-2060.

Polat, O. (2020). Frequency Connectedness and Network Analysis in Equity Markets: Evidence from G-7 Countries. Akdeniz IIIBF Dergisi, 20(2), 221-226.

Salisu, A. A., Sikiru, A. A., \& Vo, X. V. (2020). Pandemics and the emerging stock markets. Borsa Istanbul Review, 20, 40-48.

Saltoglu, B., \& Yenilmez, T. (2010). Analyzing systemic risk with financial networks an application during a financial crash (No. 26684). Germany: University Library of Munich.

So, M. K., Chu, A. M., \& Chan, T. W. (2021). Impacts of the COVID-19 pandemic on financial market connectedness. Finance Research Letters, 38, 101864.

$\mathrm{Su}, \mathrm{X}$. (2020). Measuring extreme risk spillovers across international stock markets: A quantile variance decomposition analysis. The North American Journal of Economics and Finance, 51, 101098.

Taşdemir, M., \& Yalama, A. (2014). Volatility spillover effects in interregional equity markets: Empirical evidence from Brazil and Turkey. Emerging Markets Finance and Trade, 50(2), 190-202.

The World Bank (2020). Global Economic Prospects. Retrieved from: https://www.worldbank.org/en/publication/global-economic-prospects.

Topcu, M., \& Gulal, O. S. (2020). The impact of COVID-19 on emerging stock markets. Finance Research Letters, 36, 101691.

Wang, G. J., Xie, C., Jiang, Z. Q., \& Stanley, H. E. (2016). Extreme risk spillover effects in world gold markets and the global financial crisis. International Review of Economics \& Finance, 46, 55-77.

Wen, D., Wang, G. J., Ma, C., \& Wang, Y. (2019). Risk spillovers between oil and stock markets: A VAR for VaR analysis. Energy Economics, 80, 524-535.

Yang, J., \& Zhou, Y. (2013). Credit risk spillovers among financial institutions around the global credit crisis: Firm-level evidence. Management Science, 59(10), 2343-2359. 
Polat, O. (2021). Dynamic network connectedness of BRICS equity markets during the Covid-19 era. Ömer Halisdemir Üniversitesi İktisadi ve İdari Bilimler Fakültesi Dergisi, 14(4), 1468-1498.

Etik Beyanı : Bu çalışmanın tüm hazırlanma süreçlerinde etik kurallara uyulduğunu yazarlar beyan eder. Aksi bir durumun tespiti halinde ÖHÜIİBF Dergisinin hiçbir sorumluluğu olmayıp, tüm sorumluluk çalışmanin yazarlarına aittir.

Ethics Statement $\quad$ : The author declares that ethical rules are followed in all preparation processes of this study. In case of detection of a contrary situation, ÖHÜIIBF Journal does not have any responsibility and all responsibility belongs to the author of the study. 